\title{
Neutrosophic soft set decision making for stock trending analysis
}

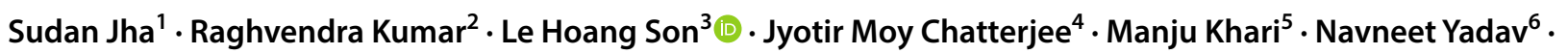 \\ Florentin Smarandache ${ }^{7}$
}

Received: 17 February 2018 / Accepted: 3 July 2018

(c) Springer-Verlag GmbH Germany, part of Springer Nature 2018

\begin{abstract}
In this paper, we point out a major issue of stock market regarding trending scenario of trades where data exactness, accuracy of expressing data and uncertainty of values (closing point of the day) are lacked. We use neutrosophic soft sets (NSS) consisting of three factors (True, Uncertainty and False) to deal with exact state of data in several directions. A new approach based on NSS is proposed for stock value prediction based on real data from last 7 years. It calculates the stock price based on the factors like "open", "high", "low" and "adjacent close". The highest score value retrieved from the score function is used to determine which opening price and high price decide the closing price from the above mentioned four factors.
\end{abstract}

Keywords Neutrosophic soft sets $\cdot$ Soft sets $\cdot$ Stock trending $\cdot$ Stock parameters $\cdot$ Open $\cdot$ Close $\cdot$ High $\cdot$ Low $\cdot$ Adjacent close

\section{Introduction}

Many fields may not be effectively demonstrated by traditional expression since vulnerability is excessively muddled. They can be demonstrated by various distinctive methodologies including the likelihood theory, fuzzy set (FS) (Zadeh 1965), rough set (Pawlak 1982), neutrosophic set (NS) (Smarandache 2005) and soft set (Molodtsov 1999). NSs can deal with uncertain and conflicting data, which exist, regularly in conviction frameworks (Wang et al. 2005). In

Le Hoang Son

sonlh@vnu.edu.vn

Sudan Jha

jhasudan@hotmail.com

Raghvendra Kumar

raghvendraagrawal7@gmail.com

Jyotir Moy Chatterjee

jyotirm4@gmail.com

Manju Khari

manjukhari@yahoo.co.in

Navneet Yadav

navneetyadavdr@gmail.com

Florentin Smarandache

fsmarandache@gmail.com

1 School of Computer Engineering, KIIT University, Bhubaneswar, India this manner, Maji proposed neutrosophic delicate set with operations, which is free of the challenges specified (Maji 2013). He additionally, connected to basic leadership issues (Maji 2012). After Maji, the investigations on the neutrosophic delicate set theory have been considered progressively (Broumi 2013; Broumi and Smarandache 2013). From scholastic perspective, the NS should be determined on the grounds that are connected to genuine applications (Deli 2017). In NS, indeterminacy is evaluated expressly and other membership degrees are free. This presumption is essential

2 Department of Computer Science and Engineering, LNCT College, Bhopal, India

3 VNU Information Technology Institute, Vietnam National University, Hanoi, Vietnam

4 School of Computer Science and Engineering, GD-RCET, Bhilai, India

5 Computer Science and Engineering Department, AIACTR, New Delhi, India

$6 \quad$ Electronics and Communication Engineering Department, Maharaja Agrasen Institute of Technology, New Delhi 110086, India

7 University of New Mexico, 705 Gurley Ave., Gallup, NM 87301, USA 
in numerous applications, for example, data combination in which the information is consolidated from various sensors. As of late, NSs had for the most part been connected to picture preparing (Cheng and Guo 2008; Guo and Cheng 2009) (Table 1).

Along these lines, Wang et al. (2010) proposed a singlevalued NS (SVNS) and set-theoretic operations and properties. Ye (2013a) proposed similarity measures between interim NSs and connected them to multi-criteria decisionmaking issues. On one hand, a SVNS is an example of a NS, which gives us an extra probability to deal with vulnerability, inadequacy and conflicting data. It would be more appropriate to apply uncertain and conflicting data measures in decision-making. In any case, the connector in the FS is portrayed concerning $T$, i.e. participation just; hereafter the information of indeterminacy and non-enrollment is lost. While in the SVNS, they can be characterized regarding any of them. Thus, the idea of SVNSs is broader and overcomes the previously mentioned issues. Then, SVNSs can be utilized for applications to handle dubious, imprecision and conflicting data. Because of its capacity, SVNS is reasonable for catching loose, indeterminate, and conflicting data in the multi-criteria decision-making.

Broumi and Smarandache (2013) presented correlation coefficients of interval valued NS (INS). Ye (2013b) exhibited the correlation coefficient of single-valued NSs (SVNSs). Ye (2014a, b) presented the idea of streamlined NSs (SNSs), which are a subclass of NSs, and characterized operational laws of SNSs. The authors proposed some accumulation administrators, including a rearranged Neutrosophic weighted number juggling normal administrator and an improved neutrosophic weighted geometric normal administrator. Peng et al. (2014, 2015) showed another outranking approach for multi-criteria decision-making (MCDM) to an improved neutrosophic condition, where reality enrollment degree, indeterminacy-participation degree and misrepresentation participation degree for every component are singleton sub-sets in Zadeh (1965). Ma et al. (2017) proposed cosine similarity measures of SNSs whereas Deli and Şubaş (2017) presented a medicinal treatment determination technique in view of an interval neutrosophic phonetic condition, in which criteria and decision-producers are doled out various levels of need. Ye (2015) introduced a philosophy for tackling multi-trait decision-making issues with SVN-numbers. Pramanik et al. (2017) proposed new vector similitude measures of single valued and interval NSs by hybridizing the ideas of Dice and cosine closeness measures. Mostly often, we see that data lack exactness, lack accuracy of expression. It is indeed necessary to use NS and its extension for dealing with these factors (Thanh et al. 2018a, b; Ali et al. 2017, 2018a, b, c; Nguyen et al. 2018; Broumi et al. 2017a, b; Dey et al. 2018; Thao et al. 2018; Thong et al. 2018; Son et al. 2017; Son and Thong 2017; Son 2015, 2016, 2017; Thong and Son 2015, 2016a, b, c; Angelov and Sotirov 2015).

This paper proposes a model for stock trend prediction based on neutrosophic soft set (NSS). Sections 2 and 3 present preliminary and the proposal. Sections 4 and 5 dive discussion, conclusions and further research respectively.

\section{Background}

Definition 1 (Molodtsov 1999) A soft set is defined as below,

$$
f: S \rightarrow \text { power_of (U) }
$$

where, $U$ and $S$ are the universal and soft sets having parameters like $R=$ redundancy contradiction, $I n c=$ inconsistency, $I n=$ incompleteness, $U_{n}=$ uncertainty, $V=$ vagueness, $A=$ ambiguity, and $I=$ imprecision undefined. Here $f$ is a mapping function to $S$.

Definition 2 (Molodtsov 1999) Let $T$ be the fuzzy soft set and $T$ be the Cross so that the Fusion and Cross can be defined as

$(\mathrm{T} \cup \mathrm{T})(x)=\mathrm{T}(x) \vee \mathrm{T}(x)$

$(\mathrm{T} \cap \mathrm{T})(x)=\mathrm{T}(x) \wedge \mathrm{T}(x)$

$\mathrm{T} \subseteq \mathrm{T}$

if $\mathrm{T}(x) \leq \mathrm{T}(x), x \in U$

where $T$ denotes the family of fuzzy soft sets $T$ (upper case), and $T$ is the Cross to define the Fusion.

Definition 3 (Molodtsov 1999) If $(f, X)$ and $\left(f^{\prime}, Y\right) \in \mathrm{U}$ then $(f, \mathrm{X})$ is fuzzy soft subset of $\left(f^{\prime}, \mathrm{Y}\right)$ or $(f, \mathrm{X}) \subseteq\left(f^{\prime}, \mathrm{Y}\right)$ if

1. $\mathrm{X} \subseteq \mathrm{Y}$

2. $\mathrm{f}(\mathrm{a}) \leq \mathrm{f}(\mathrm{a}), \mathrm{a} \in \mathrm{A}$.

Table 1 Neutrosophic soft set $(f, \mathrm{~A})$ representing the stock-trending

\begin{tabular}{llll}
\hline ST & High price & Low price & Adj close price \\
\hline Para1 & $(35.57571,35.07286,0,35.56)$ & $(37.17857,36.53286,37.03143)$ & $(38.10714,36.6,38.06714)$ \\
Para2 & $(35.87714,34.93572,35.34)$ & $(37.61286,36.67857,36.95429)$ & $(36.87714,35.53286,36.57)$ \\
Para3 & $(35.41286,34.53857,35.29572)$ & $(36.89286,28.46429,35.17857)$ & $(35.22429,32.17286,33.69429)$ \\
Para4 & $(35.60714,34.70857,34.94143)$ & $(36.37857,35.50428,36.28429)$ & $(37.12714,35.78571,36.64571)$ \\
\hline
\end{tabular}


where $(f, \mathrm{X})$ is fuzzy soft set. The difference between $(f, \mathrm{~A})$ and $(f, \mathrm{X})$ is that $(f, \mathrm{~A})$ represents Universal Neutrosophic Set whereas $(f, X)$ represents the fuzzy soft set.

All neutrosophic sets of $\mathrm{X}$ are denoted $f_{\mathrm{N}}(\mathrm{X})$.

Definition 4 (Wang et al. 2010) NSS $X$ is contained in NSS $Y$ if

1. $\mathrm{X} \subseteq \mathrm{Y}$

2. $\mathrm{TX}(\mathrm{x}) \leq \mathrm{TY}(\mathrm{x}), \mathrm{IX}(\mathrm{x}) \leq \mathrm{IY}(\mathrm{x}), \mathrm{FX}(\mathrm{x}) \geq \mathrm{FY}(\mathrm{x})$ for all $\mathrm{x}$ $\in \mathrm{X}$.

Definition 5 (Wang et al. 2010) The complement of NSS is a NSS $(f \mathrm{c}, \neg \mathrm{X})$ :

1. $f_{\mathrm{c}}: \neg \mathrm{A} \rightarrow f \mathrm{~N}(\mathrm{X})$,

2. $f \mathrm{c}(\mathrm{a})=<\mathrm{x}, \mathrm{T} f \mathrm{c}(\mathrm{x})=f f(\mathrm{x}), \mathrm{I} f \mathrm{c}(\mathrm{x})=1-\mathrm{I} f(\mathrm{x}), f f \mathrm{c}$ $(\mathrm{x})=\mathrm{T} f(\mathrm{x})>, \mathrm{a} \in \mathrm{A}$ and $\mathrm{x} \in \mathrm{X}$.

Definition 6 (Wang et al. 2010) Assume $Z=<x$, $T X(x)$, $I X(x), f^{\prime \prime} X(x)>$ and $A \leq x, T_{A}(x), I_{A}(x), f^{\prime \prime} A(x)>$ is NSS. We have

$\mathrm{X} \vee \mathrm{A} \leq \mathrm{x}, \max \left(\mathrm{TX}(\mathrm{x}), \mathrm{T}_{\mathrm{A}}(\mathrm{x})\right), \max \left(\mathrm{IX}(\mathrm{x}), \mathrm{I}_{\mathrm{A}}(\mathrm{x})\right)$, $\min \left(f^{\prime \prime} \mathrm{X}(\mathrm{x}), f^{\prime \prime} \mathrm{A}(\mathrm{x})\right)>$

$\mathrm{X} \wedge \mathrm{A} \leq \mathrm{x}, \min \left(\mathrm{TX}(\mathrm{x}), \mathrm{T}_{\mathrm{A}}(\mathrm{x})\right), \min \left(\mathrm{IX}(\mathrm{x}), \mathrm{I}_{\mathrm{A}}(\mathrm{x})\right)$, $\max \left(f^{\prime \prime} \mathrm{X}(\mathrm{x}), f^{\prime \prime} \mathrm{A}(\mathrm{x})\right)>$

Definition 7 (Wang et al. 2010) A set Z- $\neg(f, X)$ is said to be non-empty over $\mathrm{U}$ if $T_{f}(a)=0, I_{f}(a): 0, f_{f}(a): 1, a \in A$.

Definition 8 (Wang et al. 2010) Fuzzy set $(f$, A) is a Universal Neutrosophic Set over $U$ if $\mathrm{T}_{f}(\mathrm{a})=1, \mathrm{I}_{f}(\mathrm{a}): 1, \mathrm{~F}_{f}(\mathrm{a}): 0$ for all a $\in$ A.where $(f, \mathrm{~A})$ represents a fuzzy set over the universal neutrosophic set.

\section{Proposed model}

We now derive Fusion, Cross and Structure as below:

(a) Fusion of NSSs $(\mathrm{f}, \mathrm{A})$ and $\left(f^{\prime \prime}, \mathrm{B}\right)$ is $(\mathrm{H}, \mathrm{C})=(\mathrm{f}, \mathrm{A}) \cup\left(f^{\prime \prime}\right.$, $B$ ) over $U$ with $C=A \cup B$ and $H(C)=f(C)$ if $c \in A \backslash B$.

(b) Cross of NSSs (f, A) and (g, B) is $(\mathrm{H}, \mathrm{C})=(\mathrm{f}, \mathrm{A}) \cap(\mathrm{g}$, B) with $\mathrm{C}=\mathrm{A} \cap \mathrm{B}, \mathrm{H}(\mathrm{c})=\mathrm{F}(\mathrm{c}) \wedge \mathrm{G}(\mathrm{c}), \mathrm{c} \in \mathrm{C}$.

(c) Relation is computed by the following steps:
1. Let $\mathrm{L} \subseteq \mathrm{A} \times \mathrm{B}: \mathrm{L}_{\mathrm{e}}(\mathrm{a}, \mathrm{b})=f(\mathrm{a}) \wedge f^{\prime \prime}(\mathrm{b}), \mathrm{a} \in \mathrm{A}, \mathrm{b} \in \mathrm{B}$, $\mathrm{L}_{\mathrm{e}}: \mathrm{K} \rightarrow \mathrm{FN}(\mathrm{U})$.

2. $\mathrm{L}_{f l}$ in relation with $(f, \mathrm{~A})$ to $\left(f^{\prime \prime}, \mathrm{B}\right)$ and $\mathrm{L}_{f 2}$ in relation with $(f, \mathrm{~B})$ to $\left(f^{\prime \prime}, \mathrm{C}\right)$. Then, the composition of relations $\mathrm{L}_{f 1}$ and $\mathrm{L}_{f 2}$ is defined by $\left(\mathrm{L}_{f 1}{ }^{\circ} \mathrm{L}_{f 2}\right)(\mathrm{a}, \mathrm{c})=\mathrm{L}_{f 1}$ $(\mathrm{a}, \mathrm{b}) \wedge \mathrm{L}_{f 2}(\mathrm{~b}, \mathrm{c}), \mathrm{a} \in \mathrm{A}, \mathrm{b} \in \mathrm{B}, \mathrm{c} \in \mathrm{C}$.

3. The fusion and cross of $\mathrm{L}_{f l}$ and $\mathrm{L}_{f 2}$ of $(f, \mathrm{~A})$ and $\left(f^{\prime \prime}\right.$, B) over U are:

fusion $\rightarrow \mathrm{L}_{f 1} \cup \mathrm{L}_{f 2}(\mathrm{a}, \mathrm{b})=\operatorname{MAX}\left\{\mathrm{L}_{f 1}(\mathrm{a}, \mathrm{b}), \mathrm{L}_{f 2}(\mathrm{a}, \mathrm{b})\right\}$, cross $\rightarrow \mathrm{L}_{f 1} \cap \mathrm{L}_{f 2}(\mathrm{a}, \mathrm{b})=\operatorname{MIN}\left\{\mathrm{L}_{f 1}(\mathrm{a}, \mathrm{b}), \mathrm{L}_{f 2}(\mathrm{a}, \mathrm{b})\right\}$.

4. The MAX $\rightarrow$ MIN $\rightarrow$ MAX composition for set is expressed with the relation $\mathrm{L} \circ \mathrm{A}$.

5. The associative (AL), non-deterministic (NL) and nonassociative (NAL) functions can be derived as below:

$$
\begin{aligned}
& \mathrm{AL} \circ \mathrm{A}(\mathrm{y})=\mathrm{Ux}[\mathrm{AL}(\mathrm{x}) \wedge \mathrm{AA}(\mathrm{x}, \mathrm{y})], \\
& \mathrm{NL} \circ \mathrm{A}(\mathrm{y})=\cup x[\mathrm{NL}(\mathrm{x}) \wedge \mathrm{NA}(\mathrm{x}, \mathrm{y})], \\
& \mathrm{NAL} \circ \mathrm{A}(\mathrm{y})=\wedge \mathrm{x}[\mathrm{NAL}(\mathrm{x}) \vee \mathrm{NALA}(\mathrm{x}, \mathrm{y})] .
\end{aligned}
$$

6. $(f, \mathrm{~A})$ conclusively can be defined as: $\mathrm{V}(\mathrm{F}$, $\mathrm{A})=\mathrm{TA}+(1-\mathrm{UA})-\mathrm{FA}$ where $\mathrm{TA} \rightarrow$ True value, $\mathrm{UA} \rightarrow$ Uncertain value and FA $\rightarrow$ denotes the False value. The TA, UA and FA are the values with respect to $(\mathrm{F}, \mathrm{A})$.

7. Score function $\rightarrow \mathrm{S} 1=\mathrm{V}(\mathrm{F}, \mathrm{A})-\mathrm{V}(\mathrm{G}, \mathrm{B})$. The score function for $(\mathrm{L}, \mathrm{A}) \rightarrow \mathrm{TA}_{\mathrm{i}}-\mathrm{Ua}_{\mathrm{i}} * \mathrm{FA}_{\mathrm{i}}$.

Now, trade trends are identified using NSSs with variables below: Date, Open-opening price of particular date, High-highest price at particular date, Low-lowest price at particular date, Close-closing price at particular date, Adj Close - adj. close price at particular date, Volume - volume of stock traded.NSS is applied for identification, detection and determination of which stock is getting affected from various parameters. The effect $E$ relates to a closing price $C$. 


\section{NSS Algorithm for determining the decision for closing of stock trending}

Input: variables

Output: Actual and Predicated Values

Algorithm:

1. Split the data into train and test NSS data

2. The Date is the features and the Open price is our target values which need to be predicted $X($ features $)=[$ Year, Month, Day $], y($ target $)=[$ Open $]$

3. Feature scaling is done on data for faster convergence rate of algorithms and to maintain standardization in data

4. Function to plot graph is written which takes dataset as parameters and plots the graph

5. Train the model using Regression

6. The Train data are fitted into the algorithm

7. The model's accuracy is then computed by giving Test data as input and evaluating the predicted result against the known value from Test data

8. The graph is plotted between Actual value vs. Predicted value

Table 2 Obtaining the relation $L$

\begin{tabular}{llllll}
\hline Factors & Open & High & Low & Close & Adj close \\
\hline Para1 & 12.327143 & 12.368571 & 11.7 & 11.971429 & 10.770167 \\
Para2 & 12.007143 & 12.278571 & 11.97 & 12.237143 & 11.00922 \\
Para3 & 12.252857 & 12.314285 & 12.05 & 12.15 & 10.930819 \\
Para4 & 12.28 & 12.361428 & 12.18 & 12.21 & 10.984798 \\
\hline
\end{tabular}

Table 3 Performing the transformation operation using relation $T$

\begin{tabular}{lllll}
\hline Factors & Open & High & Low & Close \\
\hline Para1 & 12.444285 & 12.642858 & 12.29 & 12.321428 \\
Para2 & 12.444285 & 12.481428 & 12.141429 & 12.197143 \\
Para3 & 12.328571 & 12.378572 & 12.218572 & 12.277143 \\
Para4 & 12.347143 & 12.355714 & 12.178572 & 12.221429 \\
\hline
\end{tabular}

\section{Result and discussion}

There are sets of 7 years which include the various parameters to predict the next day opening value (https://in.finan ce.yahoo.com). The parameters achieved here are High (highest price at particular date), Low (lowest price at particular date) and Adj Close (adj. close price at particular date) Let the possible reasons relating to these ups and downs be Gold Price $\left(\mathrm{g}_{1}\right)$, Petrol Price $\left(\mathrm{pp}_{1}\right)$, Interest Rates $\left(\mathrm{ir}_{1}\right)$, the value of the US dollar $\left(\mathrm{USD}_{1}\right)$ and Economic/ Political shocks $\left(\mathrm{sh}_{1}\right)$. The following demonstrates the processing of the algorithm and achieved results.

1. Parameters of stock are sent to association $Q$.

2. Trading relating to open and closing is given in Table 2.

3. Structure $T$ of "open and close" and "high and low" is found in Step 5 (Table 3).

4. Supplement of Table 1 is shown in Table 4.

5. Supplement of Table 2 is in Table 5.

6. Estimation of Tables 4 and 5 is in Table 6.

7. Outputs of Tables 3 and 6 are given in Tables 7 and 8 independently.

8. Score associated for the qualities in Tables 7 and 8 is found in Table 9.

9. Score for Table 3 is in Table 10.

10. Find highest score for stock closing affected by different opening and closing.

From all the columns, we extract Date and Open from the table to make a new dataset.

Before decomposition of date

Date (YYYY-MM-DD) (date object)

Open (float)

Table 4 The complement of $Q \circ R$

\begin{tabular}{llll}
\hline ST & High price & Low price & Adj close price \\
\hline Para1 & $(37.02143,35.79286,35.84857,32.25138)$ & $(36.25714,35.09286,35.61857,32.04446)$ & $(35.98571,34.64143,34.74286,31.25662)$ \\
Para2 & $(35.85429,34.6,35.78714,32.19612)$ & $(36.26571,35.33857,36.21571,32.58168)$ & $(37.02143,36.28714,36.32571,32.68065)$ \\
Para3 & $(37.12143,36.5,37.09857,33.37596)$ & $(38.25,37.23286,38.17857,34.34757)$ & $(38.98571,38.5,38.83857,34.94136)$ \\
Para4 & $(39.28571,38.77428,39.15286,35.22411)$ & $(39.85857,38.39,38.59572,34.72287)$ & $(39.42429,38.78571,39.12143,35.19582)$ \\
\hline
\end{tabular}


Table 5 The complement of $\mathrm{R}^{\prime}$

\begin{tabular}{|c|c|c|c|c|}
\hline $\mathrm{R}^{\prime}$ & High & Low & Close & Adj close \\
\hline Para1 & $(39.23714,38.27143,38.71)$ & $(39.02857,38.3,38.42857)$ & $(38.61,37.97286,38.1)$ & $\begin{array}{l}(12.184286,12.042857,12.1, \\
10.885842)\end{array}$ \\
\hline Para2 & $(39.23714,38.27143,38.71)$ & $(39.02857,38.3,38.42857)$ & $(38.61,37.97286,38.1)$ & $\begin{array}{l}(12.184286,12.042857,12.1 \\
10.885842)\end{array}$ \\
\hline Para3 & $\begin{array}{l}(12.234285,12.081429, \\
12.185715,10.962953)\end{array}$ & $\begin{array}{l}(12.231428,12.111428, \\
12.172857,10.951384)\end{array}$ & $\begin{array}{l}(12.201428,12.094286, \\
12.118571,10.902546)\end{array}$ & $\begin{array}{l}(12.308572,12.022857, \\
12.271428,11.040065)\end{array}$ \\
\hline Para4 & $\begin{array}{l}(12.784286,12.28,12.742857 \\
11.46419)\end{array}$ & $\begin{array}{l}(12.972857,12.647142, \\
12.787143,11.504031)\end{array}$ & $\begin{array}{l}(12.905714,12.692857, \\
12.724286,11.447481)\end{array}$ & $\begin{array}{l}(12.857142,12.515715, \\
12.644286,11.375507)\end{array}$ \\
\hline
\end{tabular}

Table 6 Composition values of Tables 4 and 5

\begin{tabular}{lllll}
\hline $\mathrm{R}^{\prime}$ & High & Low & Close & Adj close \\
\hline Para1 & $(12.44,11.915714,11.99$, & $(12.228572,11.857142,12.087143$, & $(12.615714,11.964286,12.437143$, & $(12.505714,12.172857$, \\
& $10.786877)$ & $10.874274)$ & $11.189151)$ & $12.201428,10.977087)$ \\
Para2 & $(12.664286,12.251429,12.331429,(12.615714,12.485714,12.598572$, & $(12.71,12.492857,12.531428$, & $(12.674286,12.494286$, \\
& $11.094046)$ & $11.334381)$ & $11.273974)$ & $12.571428,11.309962)$ \\
Para3 & $(12.692857,12.485714,12.567142$, & $(12.855714,12.57,12.838572$, & $(12.201428,12.094286,12.118571,(12.308572,12.022857$, \\
& $11.306105)$ & $11.550298)$ & $10.902546)$ & $12.271428,11.040065)$ \\
Para4 & $(12.784286,12.28,12.742857$, & $(12.972857,12.647142,12.787143,(12.905714,12.692857,12.724286,(12.857142,12.515715$, \\
& $11.46419)$ & $11.504031)$ & $11.447481)$ & $12.644286,11.375507)$ \\
\hline
\end{tabular}

\begin{tabular}{lccc}
\hline \multicolumn{4}{l}{ After decomposition of date } \\
$\begin{array}{l}\text { Year (YYYY) } \\
\text { integer }\end{array}$ & $\begin{array}{c}\text { Month (MM) } \\
\text { integer }\end{array}$ & $\begin{array}{c}\text { Day (DD) } \\
\text { integer }\end{array}$ & Open (float) \\
\hline
\end{tabular}

Now, let us take Para $=\{$ para1, para2, para3, para4 $\}$ where para $1=g_{1}$, para2 $=\mathrm{pp}_{1}$, para $3=\mathrm{ir}_{1}$, and para4 $=\mathrm{USD}_{1}$ as the universal set where $\mathrm{g}_{1}, \mathrm{pp}_{1}, \mathrm{ir}_{1}$, $\mathrm{USD}_{1} \mathrm{sh}_{1}$ are Gold Price $\left(\mathrm{g}_{1}\right)$, Petrol Price $\left(\mathrm{pp}_{1}\right)$, Interest Rates $\left(\mathrm{ir}_{1}\right)$, the value of the US dollar ( $\mathrm{USD}_{1}$ ) and Economic/Political shocks $\left(\mathrm{sh}_{1}\right)$ as explained in the previous statements.

Next, consider the set $K=\{k 1, k 2, k 3, k 4\}$ as universal set where $k 1, k 2, k 3, k 4$ represent consequence/results like open, high, low and adj close respectively and the set $F=\left\{f_{1}, f_{2}, f_{3}, f_{4}\right\}$ where $f_{1}, f_{2}, f_{3}$ and $f_{4}$ represent the faster convergence rate, actual value, trending value and predicted value respectively.

We construct stock-trending relation and trending-close relation as follows:

$\mathrm{F}($ para 1$)=\{\mathrm{k} 1 /(0.7,0.4,0.1), \mathrm{k} 2 /(0.8,0.6,0.7), \mathrm{k} 3 /(0.4$, $0.8,0.5)\}$,

$\mathrm{F}($ para2 $)=\{\mathrm{k} 1 /(0.6,0.5,0.3), \mathrm{k} 2 /(0.6,0.5,0.2), \mathrm{k} 3 /(0.7$, $0.9,0.0)\}$,

$\mathrm{F}($ para3 $)=\{\mathrm{k} 1 /(0.8,0.4,0.2), \mathrm{k} 2 /(0.5,0.1,0.5), \mathrm{k} 3 /(1.0$, $0.5,1.0)\}$,

$\mathrm{F}($ para4 $)=\{\mathrm{k} 1 /(0.4,0.6,0.3), \mathrm{k} 2 /(0.5,0.4,0.8), \mathrm{k} 3 /(0.5$, $0.6,0.9)\}$. $(f, \mathrm{~A})$ results into a collection of generalized stock-trending in the stock market. It represents stock-trending relation given by,

Next, $G(k 1)=\{\mathrm{f} 1 /(37.59,36.95714,37.44143)$, f $2 /(37.85714,36.62857,36.90857), \quad \mathrm{f} 3 /$ $(36.64,35.64286,36.26), \mathrm{f} 4 /(34.92857,33.05,34.61714)\}$, $\mathrm{G}(\mathrm{k} 2)=\{\mathrm{f} 1 /(36.59714,35.38714,36.31714)$, $\mathrm{f} 2 /(36.93572,35.75143,36.05143), \mathrm{f} 3 /$ (34.83571,33.74429,33.96571), f4/ $(36.13143,34.97857,35.47714)\}, \mathrm{G}(\mathrm{k} 4)=\{\mathrm{f} 1 /(37.82857,37$ $.19,37.70714,33.92345), \mathrm{f} 2 /(37.93572,37.20153,37.58857,3$ 3.81678), f3/(37.41429,36.37571,36.56572,32.89656)\}. We realize $\{G(f 1), G(f 2), G(f 3)\}$ of all $S$ where $G: S \rightarrow F N(D)$. Thus, $(G, S)$ is represented by a relation matrix (stock_highstock_lowmatrix) R given in Table 2.

The trading knowledge relating the parameters with the set of open and closing values under consideration is in Table 2. We perform transformation operation $Q \circ R$ to get the stocks' high and low value relation in Table 3.

Likewise, $Q \circ R$ is calculated to give the stocks' high and low value relation $T$. These set of values are now complimented in Tables 4 and 5. The composition values are calculated in Table 6.

Table 6 uses the composition of relations $\mathrm{L}_{f 1}$ and $\mathrm{L}_{f 2}$ which are defined by,

$\left(L_{f 1} \circ L_{f 2}\right)(a, c)=L_{f 1}(a, b) \wedge L_{f 2}(b, c), a \in A, b \in B, c \in C$.

Value functions for Tables 3 and 6 are calculated in Tables 7 and 8. 
Table 7 The value function for cross of $L_{f 1}(a, b) \wedge L_{f 2}(b, c)$

\begin{tabular}{lllll}
\hline Value & High & Low & Close & Adj close \\
\hline Para1 & $12.78,12.28$ & 12.74 & 11.46 & Para1 \\
Para2 & 12.97 & 12.64 & 12.78 & 11.50 \\
Para3 & 12.90 & 12.69 & 12.72 & 11.44 \\
Para4 & 12.85 & 12.51 & 12.64 & 11.37 \\
\hline
\end{tabular}

Table 8 The value function for fusion of $L_{f 1}(a, b) \cup L_{f 2}(b, c)$

\begin{tabular}{lllll}
\hline Value & High & Low & Close & Adj close \\
\hline Para1 & 13.68 & 12.38 & 12.34 & 12.46 \\
Para2 & 12.79 & 12.46 & 12.78 & 12.39 \\
Para3 & 12.60 & 12.46 & 12.27 & 11.44 \\
Para4 & 12.42 & 12.24 & 12.46 & 11.37 \\
\hline
\end{tabular}

Table 9 Score function for Tables 7 and 8

\begin{tabular}{lcccl}
\hline Value & High & Low & Close & Adj close \\
\hline Para1 & -0.01 & -0.1 & -0.04 & 0.3 \\
Para2 & 0.4 & 0.3 & 0.7 & 0.6 \\
Para3 & 0.1 & 0.3 & 0.5 & 0.5 \\
Para4 & -0.7 & -0.03 & -0.04 & 0 \\
\hline
\end{tabular}

Table 10 Score function for the Table 3

\begin{tabular}{lllll}
\hline Value & High & Low & Close & Adj close \\
\hline Para1 & 0.14 & 0.3 & 0.35 & 0.65 \\
Para2 & 0.46 & 0.46 & 0.55 & 0.45 \\
Para3 & 0.55 & 0.55 & 0.75 & 0.38 \\
Para4 & 0.08 & 0.2 & 0.18 & 0.38 \\
\hline
\end{tabular}

Score function $(L, A) \rightarrow T A_{i}-U a_{i} * F A_{i}$ for Table 3 is in Table 10. As explained earlier, the score function comprises of values of high, low, close and Adjclose. The closest score function is depicted below.

It is clear from Tables 9 and 10 that stock price at para 1 and para 4 are absolute alteration due to $k 1, k 2, k 3, k 4$ represent consequence/results like open, high, low and adj close respectively.

From Table 3, $Q \circ R$ is performed to give the stocks' high and low value relation. These set of values are now complimented in Tables 4 and 5.

\section{Conclusion}

This paper applied neutrosophic soft sets to predict the stock price. Based upon the factors like open, high, low and adj close, and the score value, we have developed a technique to determine which opening price and high price decide the closing price from what factors. Since there is no competing interest exists in the field of applied NSS, there are various scopes using fuzzy theory to determine the predictability of stock parameterized values at the specific time. In our work, we have focused on the value for the opening and closing points. The work can be extended to trace the decision at any point of time. Yet, it indeed needs huge datasets for testing the model rigorously. We keep this as the reference for the future.

\section{Compliance with ethical standards}

Conflict of interest The authors declare that they do not have any conflict of interests. This research does not involve any human or animal participation. All authors have checked and agreed the submission.

\section{References}

Ali M, Son LH, Deli I, Tien ND (2017) Bipolar neutrosophic soft sets and applications in decision making. J Intell Fuzzy Syst 33(6):4077-4087

Ali M, Son LH, Thanh ND, Minh NV (2018a) A neutrosophic recommender system for medical diagnosis based on algebraic neutrosophic measures. Appl Soft Comput. https://doi.org/10.1016/j. asoc.2017.10.012

Ali M, Dat LQ, Son LH, Smarandache F (2018b) Interval complex neutrosophic set: formulation and applications in decision-making. Int J Fuzzy Syst 20(3):986-999

Ali M, Son LH, Khan M, Tung NT (2018c) Segmentation of dental $\mathrm{X}$-ray images in medical imaging using neutrosophic orthogonal matrices. Expert Syst Appl 91:434-441

Angelov P, Sotirov S (eds) (2015) Imprecision and uncertainty in information representation and processing: new tools based on intuitionistic fuzzy sets and generalized nets, vol 332. Springer, Berlin

Broumi S (2013) Generalized neutrosophic soft set. IJCSEIT. https:// doi.org/10.5121/ijcseit.2013.3202

Broumi S, Smarandache F (2013) Intuitionistic neutrosophic soft set. J Inf Comput Sci 8(2):130-140

Broumi S, Son LH, Bakali A, Talea M, Smarandache F, Selvachandran G (2017a) Computing operational matrices in neutrosophic environments: amatlab toolbox. Neutrosophic Sets Syst 18

Broumi S, Dey A, Bakali A, Talea M, Smarandache F, Son LH, Koley D (2017b) Uniform single valued neutrosophic graphs. Infinite study

Cheng HD, Guo Y (2008) A new neutrosophic approach to image thresholding. New Math Nat Comput 4(3):291-308

Deli I (2017) Interval-valued neutrosophic soft sets and its decision making. Int J Mach Learn Cybernet 8(2):665-676

Deli I, Şubaş Y (2017) A ranking method of single valued neutrosophic numbers and its applications to multi-attribute decision making problems. Int J Mach Learn Cybernet 8(4):1309-1322

Dey A, Broumi S, Bakali A, Talea M, Smarandache F (2018) A new algorithm for finding minimum spanning trees with undirected neutrosophic graphs. Granul Comput. https://doi.org/10.1007/ s41066-018-0084-7

Guo Y, Cheng HD (2009) New neutrosophic approach to image segmentation. Pattern Recognit 42:587-595 
Ma YX, Wang JQ, Wang J, Wu XH (2017) An interval neutrosophic linguistic multi-criteria group decision-making method and its application in selecting medical treatment options. Neural Comput Appl 28(9):2745-2765

Maji PK (2012) A neutrosophic soft set approach to a decision making problem. Ann Fuzzy Math Inform 3(2):313-319

Maji PK (2013) Neutrosophic soft set. Comput Math Appl 45:555-562

Molodtsov DA (1999) Soft set theory-first results. Comput Math Appl 37:19-31

Nguyen NG, Son LH, Ashour A, Dey N (2018) A survey of the stateof-the-arts on neutrosophic sets in biomedical diagnoses. Int $\mathrm{J}$ Mach Learn Cybern. https://doi.org/10.1007/s13042-017-0691-7

Pawlak Z (1982) Rough sets. Int J Inf Comput Sci 11:341-356

Peng JJ, Wang JQ, Zhang HY, Chen XH (2014) An outranking approach for multi-criteria decision-making problems with simplified neutrosophic sets. Appl Soft Comput 25:336-346

Peng JJ, Wang JQ, Wu XH, Wang J, Chen XH (2015) Multi-valued neutrosophic sets and power aggregation operators with their applications in multi-criteria group decision-making problems. Int J Comput Intell Syst 8(2):345-363

Pramanik S, Biswas P, Giri BC (2017) Hybrid vector similarity measures and their applications to multi-attribute decision making under neutrosophic environment. Neural Comput Appl 28(5):1163-1176

Smarandache F (2005) Neutrosophic set, a generalisation of the intuitionistic fuzzy sets. Int J Pure Appl Math 24:287-297

S., Broumi, \& Smarandache F (2013) Correlation coefficient of interval neutrosophic set. Trans Tech Publ Appl Mech Mater 436:511-517

Son LH (2015) DPFCM: a novel distributed picture fuzzy clustering method on picture fuzzy sets. Expert Syst Appl 42(1):51-66

Son LH (2016) Generalized picture distance measure and applications to picture fuzzy clustering. Appl Soft Comput 46(C):284-295

Son LH (2017) Measuring analogousness in picture fuzzy sets: from picture distance measures to picture association measures. Fuzzy Optim Decis Mak 16:359-378

Son LH, Thong PH (2017) Some novel hybrid forecast methods based on picture fuzzy clustering for weather nowcasting from satellite image sequences. Appl Intell 46(1):1-15

Son LH, Viet PV, Hai PV (2017) Picture inference system: a new fuzzy inference system on picture fuzzy set. Appl Intell 46(3):652-669

Thanh ND, Ali M, Son LH (2018a) Neutrosophic recommender system for medical diagnosis based on algebraic similaritymeasureand clustering. In: Fuzzy systems (FUZZ-IEEE), 2017 IEEE international conference. IEEE, Naples, pp 1-6
Thanh ND, Ali M, Son LH (2018b) A novel clustering algorithm in a neutrosophic recommender system for medical diagnosis. Cognit Comput 9(4):526-544

Thao NX, Son LH, Cuong BC, Ali M, Lan LH (2018) Fuzzy equivalence on standard and rough neutrosophic sets and applications to clustering analysis. In: Information systems design and intelligent applications. Springer, Singapore, pp 834-842

Thong NT, Son LH (2015) HIFCF: an effective hybrid model between picture fuzzy clustering and intuitionistic fuzzy recommender systems for medical diagnosis. Expert Syst Appl 42(7):3682-3701

Thong PH, Son LH (2016a) Picture fuzzy clustering for complex data. Eng Appl Artif Intell 56:121-130

Thong PH, Son LH (2016b) A novel automatic picture fuzzy clustering method based on particle swarm optimization and picture composite cardinality. Knowl Based Syst 109:48-60

Thong PH, Son LH (2016c) Picture fuzzy clustering: a new computational intelligence method. Soft Comput 20(9):3549-3562

Thong PH, Tuan TA, Minh NTH, Son LH (2018) One solution for proving convergence of picture fuzzy clustering method. In: Information systems design and intelligent applications. Springer, Singapore, pp 843-852

Wang H, Smarandache F, Zhang YQ, Sunderraman R (2005) Interval neutrosophic sets and logic: theory and applications in computing. Hexis. Neutrosophic book series, vol 5

Wang H, Smarandache F, Zhang YQ et al (2010) Single valued neutrosophic sets. MultispaceMultistruct 4:410-413

Ye J (2013a) Similarity measures between interval neutrosophic sets and their applications in multicriteria decision-making. J Intell Fuzzy Syst

Ye J (2013b) Multicriteria decision-making method using the correlation coefficient under single-valued neutrosophic environment. Int J Gen Syst 42(4):386-394

Ye J (2014a) A multicriteria decision-making method using aggregation operators for simplified neutrosophic sets. J Intell Fuzzy Syst 26(5):2459-2466

Ye J (2014b) Vector similarity measures of simplified neutrosophic sets and their application in multicriteria decision making. J Intell Fuzzy Syst 16(2):54-68

Ye J (2015) Improved cosine similarity measures of simplified neutrosophic sets for medical diagnoses. Artif Intell Med 63(3):171-179

Zadeh LA (1965) Fuzzy sets. Inform Control 8:338-353

Publisher's Note Springer Nature remains neutral with regard to jurisdictional claims in published maps and institutional affiliations. 